\title{
BMJ Open Setting research priorities to improve the health of children and young people with neurodisability: a British Academy of Childhood Disability-James Lind Alliance Research Priority Setting Partnership
}

\begin{abstract}
Christopher Morris, ${ }^{1}$ Doug Simkiss, ${ }^{2}$ Mary Busk, ${ }^{3}$ Maureen Morris, ${ }^{3}$ Amanda Allard, ${ }^{4}$ Jacob Denness, ${ }^{4}$ Astrid Janssens, ${ }^{1}$ Anna Stimson, ${ }^{1}$ Joanna Coghill, ${ }^{5}$ Kelly Robinson, ${ }^{6}$ Mark Fenton, ${ }^{7}$ Katherine Cowan ${ }^{8}$
\end{abstract}

To cite: Morris C, Simkiss D, Busk M, et al. Setting research priorities to improve the health of children and young people with neurodisability: a British Academy of Childhood Disability-James Lind Alliance Research Priority Setting Partnership. BMJ Open 2015;5:e006233.

doi:10.1136/bmjopen-2014006233

- Prepublication history and additional material is available. To view please visit the journal (http://dx.doi.org/ 10.1136/bmjopen-2014006233).

Received 29 July 2014 Revised 21 October 2014 Accepted 17 November 2014

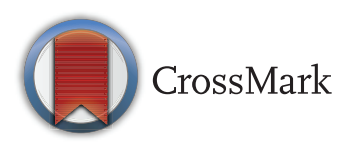

For numbered affiliations see end of article.

Correspondence to Dr Christopher Morris; christopher.morris@exeter. ac.uk

\section{ABSTRACT}

Objectives: To engage young people, parent carers and clinicians in a systematic process to identify and prioritise research questions regarding ways to improve the health and well-being of children and young people with neurodisability.

Design: British Academy of Childhood Disability (BACD)-James Lind Alliance research priority setting partnership bringing together patients, carers and clinicians as equal stakeholders.

Setting: UK health service and community. Methods: The BACD Strategic Research Group formed the partnership. A Steering Group was established; charity and professional partner organisations were recruited. Suggestions were gathered in an open survey and from research recommendations for statutory guidance. Items were aggregated to formulate indicative research questions and verified as uncertainties from research evidence. An interim survey was used to rank the questions to shortlist topics. A mixed group of stakeholders discussed the top 25 questions at the final priority setting workshop agreeing a final rank order and the top 10 research priorities.

Participants: Partner organisations were 13 charities and 8 professional societies. 369 people submitted suggestions ( $40 \%$ non-clinicians). 76 people participated in the interim prioritisation (26 parents, 1 young person, 10 charity representatives, 39 clinicians); 22 took part in the final workshop (3 young people, 7 parents, 3 charity representatives, 9 professionals).

Results: The top three research priorities related to (1) establishing the optimal frequency and intensity (dose) for mainstream therapies, (2) means for selecting and encouraging use of communication strategies and (3) ways to improve children's attitudes towards disability. The top 10 included evaluating interventions to promote mobility, self-efficacy, mental

\section{Strengths and limitations of this study}

Systematic and transparent process that included stakeholders that have often not had a say in setting the research agenda;

- Young people, parent carers and clinicians agreed on the top 10 priority topics;

- Non-categorical approach to neurodisability produced research questions that need to be answered for the broad population of children and young people;

- Non-categorical approach will exclude specific issues for children and young people with a particular diagnosis or syndrome;

- The scope focused on interventions and process cannot identify all potential research questions; therefore, some important topics were not included;

- Methodological challenges included engaging young people in the survey and the many issues raised that could not be framed as research questions.

health, continence, physical fitness, educational inclusion and reduce impacts of sleep disturbance. Conclusions: The methodology provided a systematic and transparent process to identify research priorities that included stakeholders that have typically not contributed to setting the research agenda. The top 10 and other topics identified provide a resource for researchers and agencies that fund research

\section{BACKGROUND}

Patients, carers and members of the public are encouraged to become involved as partners in research. ${ }^{1}{ }^{2}$ Patient and public 
involvement is mandatory in the UK for health research funded through public taxation. Similar strategies are being adopted for instance in Canada, USA and Australia, using analogous terms. Patient and public involvement in health research is philosophically correct, believed to confer pragmatic benefits that improve the utility and conduct of research, and has positive impacts on the people involved. ${ }^{3-5}$

A key issue in applied health research is deciding which research questions are addressed and investigated. In the past, researchers have generally decided the research topics ${ }^{6}$ and, unintentionally, have tended to pursue their perceived priorities which may not be the same as those of patients and carers. ${ }^{7}$ At worst, this leads to research findings that do not inform real-world decisions and are wasteful of scarce resources. ${ }^{8}$ Hence, increasingly, there is a role for patients, carers and nonresearch active clinicians in shaping research agendas. ${ }^{9} 10$ To fulfil this aspiration detailed methodologies require to be developed; these methods require advertising and explaining the opportunities to be involved, moving from issues of interest to framing tractable research questions and finding ways to prioritise topics identified by taking account of the various complexities and competing preferences.

The James Lind Alliance (JLA) is a non-profit making initiative established in 2004 and now coordinated by the National Institute for Health Research (NIHR) to support patients, carers and clinicians working together to agree on the most important treatment uncertainties for particular health conditions. ${ }^{11}$ The JLA definition of a treatment uncertainty is that no up-to-date, reliable systematic reviews exist or up-to-date systematic reviews confirm equipoise. The JLA methodology aims to make patients and carers as empowered as clinicians in all stages in the process. The JLA process is about hearing the voices of patients, carers and clinicians who, unlike researchers and industry, do not normally have an opportunity to influence the research agenda. Without their voices, areas of potentially important research that could inform decisions may be neglected. The JLA exists to redress this imbalance. The role of researchers in taking issues forward is well recognised and the JLA is keen to work with researchers who have an interest in the shared priorities of patients, carers and clinicians to make use of the results of the priority setting process. The JLA methods are in many ways defined and transparent, although these are constantly developing; they encourage flexibility to meet the needs of particular contexts and groups.

Neurodisability is an umbrella term for conditions associated with impairment of the nervous system, such as cerebral palsy, autism, epilepsy and an array of less common syndromes (box 1). ${ }^{12}$ Research activity in neurodisability has been observed to be associated with severity and prevalence of particular conditions, although there are exceptions. ${ }^{13}$ Recent growth in research was noted not to be proportionate to the severity or numbers of

\section{Box 1 Definition of neurodisability}

What is 'neurodisability'?

For the purposes of this project: "Neurodisability describes a group of congenital or acquired long-term conditions that are attributed to impairment of the brain and or neuromuscular system and create functional limitations. A specific diagnosis may or may not be identified. Conditions may vary over time, occur alone or in combination, and include a broad range of severity and complexity. The impact may include disturbances of movement, cognition, hearing and vision, communication, emotion and behaviour".

comorbidities, and greater for autism and attention deficit hyperactivity disorder (ADHD) ${ }^{13}$ The British Academy of Childhood Disability (BACD) is a UK organisation for professionals working with children and young people with all forms of disability (http://www.bacdis.org. uk/about). BACD is committed to collaborating closely with families of disabled children and includes parent carers in its management structure. One of the key aims of the Strategic Research Group (SRG) of BACD is to encourage and assist people in the field, including families and clinicians, to identify research priorities. ${ }^{14}$ The BACD Executive Committee and SRG established a working group for a JLA Research Priority Setting Partnership (PSP) focusing on neurodisability in 2012 and provided funding. The initiative took a noncategorical approach to identify treatment uncertainties that were common across neurodisability; however, we recognised that some issues that might arise would be specific to particular conditions.

The BACD Executive and SRG set the scope as "any ways to improve the health and/or well-being of children and young people with neurodisability where there is uncertainty of the effectiveness of an intervention, therapy or procedure". Each term in the scope was defined (see online supplementary file 1); interventions were broadly any environmental factor in the International Classification of Functioning Disability and Health (ICF). ${ }^{15}$ The SRG advised on methods to increase community participation but then had no further role to receive progress reports.

The objectives of the BACD-JLA Childhood Disability Research PSP were to: (1) enable patients, parent carers and clinicians to identify treatment uncertainties, (2) agree by consensus on a prioritised list, (3) publicise the results and processes and (4) promote the priorities to researchers and funding agencies.

\section{METHODS}

The methodology followed guidance recommended in the JLA Guidebook. ${ }^{16}$

\section{Steering Group}

A Steering Group was convened with patient, carer and clinician representatives. Two members were from the 
National Network of Parent Carer Forums (NNPCF, http://www.nnpcf.org.uk), a young adult and charity representative from the Council for Disabled Children, a paediatrician, a researcher (and former allied health professional), the editor of the UK Database of Uncertainties about the Effects of Treatments (UK DUETs), and was chaired by a JLA advisor.

The group met on seven occasions at key stages in the project and discussed matters arising in between by teleconference calls. Travel expenses were reimbursed and the time of non-salaried members was acknowledged at $£ 75$ per meeting. No formal training was provided; the JLA advisor supported the group throughout to understand steps and processes, for example, framing research questions.

\section{Partner organisations and societies}

Disability and condition-specific charitable organisations supporting families of children and young people with neurodisability, and professional societies and special interest groups were made aware of the project and invited to become partners. Members of the Steering Group approached representatives of some organisations through personal contacts; other organisations were invited to take part through their generic email address and some charities approached the PSP themselves. Agencies commissioning childhood disability research were also made aware of the project. Partners were listed on the PSP website (http://www.bacdis.org.uk/ research/psp.htm).

\section{Identifying uncertainties}

Uncertainties were gathered from families and clinicians through a survey and from research recommendations in the UK and WHO guidance documents.

The Steering Group reviewed examples of questions and formats for administering the survey used in JLA PSPs for other conditions. There was debate on an open question approach versus a more structured format asking for specification of particular patients, intervention, comparator and outcome (PICO). On balance, an open approach was preferred to enable people to express themselves freely; additional questions were included to identify key characteristics of people participating in the survey, and an option to provide an email or postal address to be kept informed about the project.

An online survey was set up as the predominant way to gather uncertainties; the format was piloted and refined following feedback. A link to the survey was then forwarded to partner organisations and societies, and advertised by them using various media, such as newsletters; an invitation was forwarded to the contact person at child development teams on the BACD database and the link was also available on the BACD PSP website. Printed copies of the questionnaire were made available at several events for parent carers and young people with freepost return envelope; these data were then entered into the online survey.
The Steering Group monitored responses to the survey and under-represented groups were more purposively targeted while the survey was live. For example, work was undertaken by the NNPCF to promote the survey more actively to parent carers by making clearer the benefits of taking part and the Council for Disabled Children provided opportunities to include the views of children and young people at their events.

Research recommendations were extracted from relevant guidance from the National Institute for Health and Care Excellence (NICE), Scottish Intercollegiate Guidance Network (SIGN), and by scanning relevant topics in the Cochrane Library (by JC in consultation with DS). Research recommendations from the World Report on Disability ${ }^{17}$ were also examined (by CM).

\section{Organising uncertainties}

Survey suggestions and person identification data were downloaded from the online database. The Steering Group reviewed a subset of the submissions. Each was discussed in turn to decide whether it was within the scope of the project and then whether a PICO structured research question could be formulated.

Two authors reviewed all submissions and discussed the topics raised $(\mathrm{CM} / \mathrm{AJ})$. A coding approach was developed to identify issues suggested as: (1) in/out of scope, (2) symptom/impairment, (3) condition, and (4) intervention. Two people (CM/AJ) coded $50 \%$ submissions independently, compared results and discussed reasons for disagreements. Once a consistent approach was agreed, CM coded all data. Three lists of survey suggestions were presented at the subsequent Steering Group meeting, that is, those that were in scope, out of scope or borderline; more discussions focused on borderline cases and final decisions were agreed.

\section{Refining research questions from uncertainties}

Aggregating survey suggestions by type of impairment or diagnosis, and by intervention enabled broadly similar suggestions to be grouped together. A research question was then drafted for each issue. The Steering Group reviewed each research question and considered whether the wording should be revised.

\section{Checking uncertainties}

The veracity of whether research questions were uncertain was checked by reference to published systematic reviews. The databases searched were the Cochrane Library (http://www.thecochranelibrary.com/view/0/index.html), NHS Centre for Reviews and Dissemination (http://www. crd.york.ac.uk/CRDWeb) and Prospero (http://www.crd. york.ac.uk/PROSPERO). The WHO International Clinical Trials Search Portal (apps.who.int/trialsearch) was searched to identify any ongoing trials.

One person $(\mathrm{CM})$ conducted the search and a second person (DS) audited these data by repeating searches to propose adding or removing of any references. Uncertainty was confirmed if there was: (1) no review, 
(2) one or more recent, relevant and reliable review(s) indicated an equivocal answer or (3) an out-of-date review (over 3 years old) indicated an equivocal answer. We also consulted several topic experts in various fields to help make decisions.

Data were managed in a spreadsheet and prepared as per the specification for entry into UK DUETs (by AS and $\mathrm{CM}) .{ }^{16}$ Research recommendations from NICE, SIGN and the World Report on Disability were integrated. The data set was checked by the UK DUETs' database manager (MF), and edited accordingly.

\section{Interim prioritisation}

The Steering Group approved a 'long list' of research questions. The long list and a questionnaire to indicate rankings of the top 10 preferences for priorities was sent to partner organisations, and people who participated in the original survey and had provided a contact email or postal address. Returns in the interim prioritisation survey were categorised into one of the three types of stakeholders (young person or parent/carer; organisations supporting families; clinicians and professional societies). The rankings were entered into a spreadsheet for analysis of the more popular prioritised questions within each stakeholder group. Each submission was scored such that a question with rank 1 was given 10 points, rank 2 had 9 points and rank points went down such that rank 10 was given 1 point. Points for each group were tallied separately; so each of the three groups ended up with its own total for each of the 53 questions. Within each group, the totals for each question were put into rank order and given a new score, from most to least popular. Where a question had not been ranked at all, it was given 0 points. Questions that had the same total were given an average score between them.

The Steering Group considered the ratings and agreed on a short list of 25 questions based on an aggregated score across stakeholder groups; these questions were taken forward for consideration at the final priority setting workshop.

\section{Priority setting workshop}

A face-to-face stakeholder meeting was convened to discuss, agree and rank a shared view of research priorities. The Steering Group invited 24 participants and sought to balance the different types of stakeholders. Partner organisations and societies were invited to nominate representatives; Council for Disabled Children (CDC) invited young people with neurodisability and NNPCF invited parent carers. A broad range of clinicians were invited, including occupational therapists, physiotherapists, speech and language therapists, nurses, paediatricians, teachers, surgeons, clinical psychologists and psychiatrists. Non-salaried participants were offered an acknowledgement for their time (£75); travel expenses were reimbursed.
The workshop agenda was structured based on JLA recommended guidance. ${ }^{16}$ The approach is a variation of nominal group methodology that seeks to ensure all stakeholders are able to voice their views equally. ${ }^{18}$ Participants were provided with the 25 questions in advance and asked to rank them. Three independent facilitators managed all discussions. Initially, participants worked in three mixed small groups; then the composition of the groups was changed; and finally, all the participants worked collectively. The shortlisted questions were presented on one side of large cards; on the other side were the ranked positions from each stakeholder group from the interim prioritisation. Facilitators used this information to encourage debate after participants discussed their personal preferences. At each stage, the cards were arranged and rearranged in order of importance based on group preferences. If broad agreement was not apparent then a vote was used. The final rank ordering represented the priorities set.

\section{Dissemination}

The Steering Group developed a dissemination strategy in advance of the final priority setting workshop; the plan included using a variety of media to reach different audiences to share the priorities with research funding agencies, and also our experiences and lessons learnt.

\section{Ethics statement}

The JLA methodology has public and patient involvement in research. The people who take part in the survey and priority setting stages of the work are not research participants. Thus, there is no requirement for ethics approval.

\section{RESULTS}

The PSP engaged a variety of stakeholder organisations and societies as partners; however, this early stage of the process took longer than anticipated. It took more to engage professional societies rather than charities, which readily joined the partnership. Partners included 13 charities and 8 professional societies or special interest groups.

There were 475 registrants to the survey, of which 369 people submitted 809 suggestions of uncertainties $(40 \%$ were non-clinicians); 106 people registered but made no suggestions, of which 42 provided an email address to be kept informed. There was considerable disagreement when two researchers coded the suggestions independently (40\%), but following a discussion a consistent approach was agreed on. After removing 453 out-of-scope suggestions, 356 items remained. Reasons for items being considered out-of-scope were that they pertained to cure or screening, no intervention was specified and no intervention could be inferred. The Steering Group reviewed and agreed on including/excluding those items coded as 'maybe' and 'out-of-scope'. A third of the final in-scope suggestions were from non-clinicians (table 1); 
Table 1 Participants in the survey to identify uncertainties and source of suggestions classified as in-scope

\begin{tabular}{|c|c|c|c|c|c|c|}
\hline & \multicolumn{2}{|c|}{$\begin{array}{l}\text { Registered for } \\
\text { survey }(n=475)\end{array}$} & \multicolumn{2}{|c|}{$\begin{array}{l}\text { Submitted at } \\
\text { least one } \\
\text { suggestion } \\
(n=369)\end{array}$} & \multicolumn{2}{|c|}{$\begin{array}{l}\text { Source of } \\
\text { suggestions } \\
\text { within scope } \\
(n=356)\end{array}$} \\
\hline \multicolumn{7}{|l|}{ Stakeholder } \\
\hline Paediatrician & 44 & 9.3 & 40 & 10.8 & 49 & 13.8 \\
\hline Nurse & 12 & 2.5 & 10 & 2.7 & 11 & 3.1 \\
\hline Speech and language therapist & 29 & 6.1 & 19 & 5.1 & 12 & 3.4 \\
\hline Physiotherapist & 61 & 12.8 & 55 & 14.9 & 72 & 20.2 \\
\hline Occupational therapist & 39 & 8.2 & 35 & 9.5 & 49 & 13.8 \\
\hline Orthotist/prosthetist & 4 & 0.8 & 4 & 1.1 & 6 & 1.7 \\
\hline Academic/researcher & 2 & 0.4 & 2 & 0.5 & 1 & 0.3 \\
\hline Specialist health visitor & 1 & 0.2 & 1 & 0.3 & 1 & 0.3 \\
\hline Audiologist & 1 & 0.2 & 0 & 0 & 0 & 0 \\
\hline Orthotist & 1 & 0.2 & 1 & 0.3 & 0 & 0 \\
\hline Administrator or manager & 1 & 0.2 & 1 & 0.3 & 0 & 0 \\
\hline GP & 2 & 0.4 & 6 & 1.6 & 1 & 0.3 \\
\hline Health professional (not further specified) & 11 & 2.3 & 1 & 0.3 & 3 & 0.8 \\
\hline Parent and health professional & 5 & 1.1 & 2 & 0.5 & 10 & 2.8 \\
\hline Part of an organisation supporting disabled people & 29 & 6.1 & 2 & 0.5 & 8 & 2.2 \\
\hline Parent, carer, relative of someone with neurodisability & 183 & 38.5 & 138 & 37.4 & 103 & 28.9 \\
\hline Young person aged 24 or under with neurodisability & 11 & 2.3 & 6 & 1.6 & 3 & 0.8 \\
\hline Wales & 10 & 2.1 & 6 & 1.6 & 4 & 1.1 \\
\hline Outside UK & 3 & 0.6 & 2 & 0.5 & 2 & 0.6 \\
\hline Missing data & 246 & 51.8 & 197 & 53.4 & 234 & 65.7 \\
\hline Total & 475 & 100 & 369 & 100 & 356 & 100 \\
\hline
\end{tabular}

approximately, half of the out-of-scope suggestions were from non-clinicians. After coding, 71 potential research questions were identified. The Steering Group discussed and reduced this list to 57 items by merging similar issues. All were confirmed as uncertainties from research findings based on the JLA criteria with reference to systematic reviews where available. Topic experts consulted, for example, regarding orthopaedic management or management of sleep disturbance, confirmed equipoise based on high-quality research evidence, even if their personal views were less uncertain.

Three questions focused on the timing, intensity and duration of physical, occupational or speech and language therapies; these were merged as one item. Fifty-three candidate questions were included in the interim prioritisation survey (see online supplementary file 2). Responses were received from 76 participants: 26 parents and 1 young person, 10 representatives from eight charities, 39 clinicians. Scores were added across the three groups resulting in a ranked list and 25 questions were taken forward to the final prioritisation workshop.

Participants in the final prioritisation meeting came from various regions of England. There were 3 young adults with neurodisability, 7 parent carers, 3 representatives from generic child disability charities, a disability 
advisor in education and 8 health professionals (paediatrician, speech and language therapist, 3 physiotherapists, occupational therapist, nurse, orthopaedic surgeon); two other professionals sent apologies on the day. Three representatives from NIHR observed the meeting.

Rationales for prioritisation we observed in the discussions included the number of children likely to benefit and the intensity of the impact of the symptom, broader consequences for families, likelihood of research informing clinical, policy or family decisions. The rankings from the first small groups were compared and aggregated; further discussions in the same and different small groups led to modifications to the ordering. Finally, all participants discussed the 25 research topics together in a plenary session, and a rank order and top 10 were agreed (table 2, box 2). Minor modifications suggested by participants at the workshop were made to some questions. A summary of the process and numbers at each stage is illustrated in figure 1 .

The top priority issue across all stakeholders in the interim survey and in the final workshop with small groups relates to the timing and intensity of physical, occupational, and speech and language therapy. The question asks whether therapies are more effective if implemented when children are younger and whether there is an optimum 'dose' (intensity, frequency, duration) for the therapy to be effective. The second priority relates to the appropriate selection of augmentative and alternative communication strategies; this priority also includes evaluating ways to encourage people to use the strategies in everyday life. The third priority is for research to evaluate 'child-focused' interventions to promote positive attitudes towards disability among children and young people in the general population. The 'top 10' priorities also included a call for research to evaluate various treatments and therapies to promote mobility, self-efficacy, mental health, continence, physical fitness, educational inclusion, and reduce the impacts on the child and family from sleep disturbance.

In terms of dissemination, this paper is an academic output describing the process; a plain language summary will be made available and separate documents are being used to publicise the findings (see online supplementary files 2 and 3). Engaging NIHR staff in the process has raised the profile of the PSP and priority research topics. The top 10, ranked 25, and all 53 topics are being sent to relevant NIHR programmes, UK Research Councils and research charities identified by the Steering Group, with attention drawn to specific topics within the scope of each agency (eg, technology appraisal, public health and education).

\section{DISCUSSION}

The BACD-JLA Childhood Disability Research PSP brought together patients, carers and clinicians to identify and rank research questions. The longer list of
53 questions and top 10 'shared priorities' provide a resource to inform commissioning decisions in government and charitable agencies that fund research. The uncertainties raised and prioritised are the outcome of a systematic and transparent process that includes stakeholders that have often not had a say in setting the research agenda. However, the process cannot feasibly identify all potential research questions from stakeholders and researchers did not contribute their ideas to the survey; therefore, some other topics were not identified and considered. Thus, our results should be considered 'a top 10' shared priorities based on those who engaged and participated in the process, rather than 'the definitive top 10'. We suspect that a different sample of stakeholder participants might not necessarily produce precisely the same result. The JLA advised that the inclusion of issues that researchers do not necessarily consider as research priorities is actually a mark of success of the process. We received guidance from the JLA Advisory Group that prioritisation should not be influenced by methodological challenges and the feasibility of addressing the research questions. While researchers were less represented in the partnership, given the JLA focus on giving patients, carers and clinicians a say in setting the research agenda, the engagement of researchers who are keen to undertake research to address their priorities is essential. We hope researchers and funding agencies will consider seriously these priority topics to influence directions for future evaluative research in this area.

Many of the research questions are necessarily broad in order to capture the wide range of issues raised in the survey and research recommendations, and for reflecting the focus on neurodisability. Hence, these 'indicative questions' represent topics for research. The process shows how much there is in common in the questions that need to be answered for children and young people with neurodisability. This reflects experience on the ground from the many thousands of families that belong to pan-disability Parent Carer Forums that are part of the NNPCF. Nevertheless, some issues that arose were specific to certain conditions. The original text of survey submissions and research recommendations are available in UK DUETs. Considerable refinement will be required in order to take each topic forward as a feasible substantive project. In some cases it would be sensible to design studies with more defined subsets of this population with particular characteristics, diagnosis or age groups. Most of the questions encompass a range of interventions that would not be realistic to investigate in a single study. Therefore, a specific intervention and comparator would need to be selected and/or a therapy regimen carefully defined. Relevant outcomes need to be specified and decisions made about how and when the outcomes should be measured. We advocate that families should be consulted about these decisions, consistent with the ethos of patient and public involvement. Consistent with the ethos of the PSP, we would also want 
Table 2 Final ranking order priority of the questions, including history of rank order from the interim survey and small groups

\begin{tabular}{|c|c|c|c|c|c|c|c|c|c|c|c|c|c|}
\hline \multirow[b]{2}{*}{ Question considered } & \multicolumn{4}{|c|}{ Interim survey } & \multicolumn{4}{|c|}{ Workshop first groups } & \multicolumn{4}{|c|}{ Second small groups } & \multirow[b]{2}{*}{$\begin{array}{l}\text { Final } \\
\text { rank }\end{array}$} \\
\hline & $\begin{array}{l}\text { Family } \\
\text { score }\end{array}$ & $\begin{array}{l}\text { Clinician } \\
\text { score }\end{array}$ & $\begin{array}{l}\text { Charity } \\
\text { score }\end{array}$ & $\begin{array}{l}\text { Collated } \\
\text { rank }\end{array}$ & $\begin{array}{l}\text { K-1 } \\
\text { rank }\end{array}$ & $\begin{array}{l}\text { S-1 } \\
\text { rank }\end{array}$ & $\begin{array}{l}\text { L-1 } \\
\text { rank }\end{array}$ & $\begin{array}{l}\text { Collated } \\
\text { rank }\end{array}$ & $\begin{array}{l}\mathrm{K}-2 \\
\text { rank }\end{array}$ & $\begin{array}{l}\text { S-2 } \\
\text { rank }\end{array}$ & $\begin{array}{l}\text { L-2 } \\
\text { rank }\end{array}$ & Collated & \\
\hline $\begin{array}{l}\text { Does the timing and intensity of 'early' } \\
\text { intervention (eg, providing information, } \\
\text { physiotherapy, speech and language } \\
\text { therapy, occupational therapy, etc) alter } \\
\text { effectiveness of therapies for infants and } \\
\text { young children with neurodisability, including } \\
\text { those without specific diagnosis? What is the } \\
\text { appropriate age of onset/strategies/dosage/ } \\
\text { direction of therapy interventions? }\end{array}$ & 1 & 1 & 1 & 1 & 1 & 1 & 1 & 1 & 1 & 1 & 1 & 1 & 1 \\
\hline $\begin{array}{l}\text { To improve communication for children and } \\
\text { young people with neurodisability: }(A) \text { what is } \\
\text { the best way to select the most appropriate } \\
\text { communication aids? and (B) how to } \\
\text { encourage staff/carers to use aids to enable } \\
\text { communication? }\end{array}$ & 3 & 5 & $10=$ & 3 & 2 & 2 & 5 & 2 & 2 & 2 & 2 & 2 & 2 \\
\hline $\begin{array}{l}\text { Are strategies to improve children's (ie, } \\
\text { peers) attitudes towards disability (eg, buddy } \\
\text { or circle of friends, etc) effective to improve } \\
\text { inclusion and participation within educational, } \\
\text { social and community settings? }\end{array}$ & $10=$ & 4 & $2=$ & 4 & 3 & 4 & 6 & 3 & 3 & 3 & 3 & 3 & 3 \\
\hline $\begin{array}{l}\text { Does appropriate provision of wheelchairs to } \\
\text { enable independent mobility for very young } \\
\text { children improve their self-efficacy? }\end{array}$ & 22 & 14 & 22 & 24 & 5 & 8 & 2 & 4 & 4 & 4 & 4 & 4 & 4 \\
\hline $\begin{array}{l}\text { Is counselling/psychological intervention } \\
\text { effective to promote the mental health of } \\
\text { children and young people with } \\
\text { neurodisability? }\end{array}$ & 18 & 23 & $6=$ & 17 & 4 & 5 & 14 & 6 & 6 & 6 & 6 & 6 & 5 \\
\hline $\begin{array}{l}\text { What is the (long-term) comparative safety } \\
\text { and effectiveness of medical and surgical } \\
\text { spasticity management techniques (BoNT-A, } \\
\text { SDR, ITB, orally administered medicines) in } \\
\text { children and young people with } \\
\text { neurodisability? }\end{array}$ & 16 & $8=$ & 12 & 8 & 12 & 13 & 4 & 7 & 7 & 7 & 5 & 7 & 6 \\
\hline $\begin{array}{l}\text { Does a structured training programme, } \\
\text { medicines and/or surgery speed up the } \\
\text { achievement of continence (either/or faecal } \\
\text { or urinary) for children and young people } \\
\text { with neurodisability? }\end{array}$ & $6=$ & 20 & $19=$ & 15 & 16 & 16 & 7 & 12 & 8 & 8 & 9 & 8 & 7 \\
\hline $\begin{array}{l}\text { What strategies are effective to improve } \\
\text { engagement in physical activity (to improve }\end{array}$ & 17 & 7 & 21 & 14 & 20 & 6 & 8 & 9 & 9 & 9 & 13 & 9 & 8 \\
\hline
\end{tabular}

Does the timing and intensity of 'early'

(evion (eg, providing information,

hysiotherapy, speech and language

effectiveness of 1

young children with neurodisability, including

without specific diagnosis? What is the

(

communication aids? and (B) how to

encourage staff/carers to use aids to enable

peers) attitudes towards disability (eg, buddy

(o improve

social and community settings?

children and young people with

rodisability?

What is the (long-term) comparative safety

children and young people with

eurodisability?

Does a structured training programme,

What strategies are effective to improve

engagement in physical activity (to improve 


\section{Question considered}

fitness, reduce obesity, etc) for children and young people with neurodisability?

Which school characteristics (eg, policies, attitudes of staff, etc) are most effective to promote inclusion of children and young

people with neurodisability in education and after-school clubs?

What is the safety and effectiveness of melatonin (or other drugs) compared to behavioural strategies to manage sleep

disorders in children and young people with neurodisability?

What is the safety and effectiveness of drugs compared to cognitive behavioural therapy to treat anxiety in children and young people with ASDs?

Are any types of physical therapy (eg, Bobath, Neuro-Developmental Therapy,

hydro, constraint, strength-training, etc) more or less effective to promote motor functioning in children and young people with

neurodisability (eg, cerebral palsy, acquired brain injury)?

Are sensory processing/integration

therapeutic programmes effective in

improving behaviour and/or increasing play/ participation for children and young people

with neurodisability?

Are behavioural and sensory interventions

(eg, early intensive behavioural intervention,

EarlyBird, enforced socialisation with peers,

etc) effective in managing symptoms of

ASD?

Are postural management programmes

(using standing frames and sleep systems,

etc) effective and cost-effective to prevent

deformity (hip and/or spine) and improve

function in children and young people with

neurodisability? What is the incidence of

\begin{tabular}{|c|c|c|c|c|c|c|c|c|c|c|c|c|}
\hline \multicolumn{4}{|c|}{ Interim survey } & \multicolumn{4}{|c|}{ Workshop first groups } & \multicolumn{4}{|c|}{ Second small groups } & \multirow[b]{2}{*}{$\begin{array}{l}\text { Final } \\
\text { rank }\end{array}$} \\
\hline $\begin{array}{l}\text { Family } \\
\text { score }\end{array}$ & $\begin{array}{l}\text { Clinician } \\
\text { score }\end{array}$ & $\begin{array}{l}\text { Charity } \\
\text { score }\end{array}$ & $\begin{array}{l}\text { Collated } \\
\text { rank }\end{array}$ & $\begin{array}{l}\mathrm{K}-1 \\
\text { rank }\end{array}$ & $\begin{array}{l}\text { S-1 } \\
\text { rank }\end{array}$ & $\begin{array}{l}\text { L-1 } \\
\text { rank }\end{array}$ & $\begin{array}{l}\text { Collated } \\
\text { rank }\end{array}$ & $\begin{array}{l}\text { K-2 } \\
\text { rank }\end{array}$ & $\begin{array}{l}\text { S-2 } \\
\text { rank }\end{array}$ & $\begin{array}{l}\text { L-2 } \\
\text { rank }\end{array}$ & Collated & \\
\hline 20 & 10 & 4 & 7 & 11 & 3 & 22 & 10 & 10 & 13 & 10 & 10 & 9 \\
\hline 14 & 19 & 8 & 12 & 8 & 22 & 16 & 17 & 19 & 10 & 17 & 15 & 10 \\
\hline 25 & 21 & $2=$ & 20 & 18 & 12 & 3 & 8 & 14 & 11 & 8 & 11 & 11 \\
\hline 2 & 2 & 5 & 2 & 7 & 7 & 9 & 5 & 5 & 5 & 7 & 5 & 12 \\
\hline 8 & $8=$ & $6=$ & 5 & 14 & 21 & 10 & 16 & 11 & 18 & 12 & 12 & 13 \\
\hline $23=$ & 17 & 17 & 21 & 9 & 15 & 17 & 13 & 15 & 12 & 15 & 13 & 14 \\
\hline 21 & 6 & $15=$ & 13 & 13 & 14 & 11 & 11 & 13 & 15 & 14 & 14 & 15 \\
\hline
\end{tabular}




\begin{tabular}{|c|c|c|c|c|c|c|c|c|c|c|c|c|c|}
\hline \multirow[b]{2}{*}{ Question considered } & \multicolumn{4}{|c|}{ Interim survey } & \multicolumn{4}{|c|}{ Workshop first groups } & \multicolumn{4}{|c|}{ Second small groups } & \multirow[b]{2}{*}{$\begin{array}{l}\text { Final } \\
\text { rank }\end{array}$} \\
\hline & $\begin{array}{l}\text { Family } \\
\text { score }\end{array}$ & $\begin{array}{l}\text { Clinician } \\
\text { score }\end{array}$ & $\begin{array}{l}\text { Charity } \\
\text { score }\end{array}$ & $\begin{array}{l}\text { Collated } \\
\text { rank }\end{array}$ & $\begin{array}{l}\mathrm{K}-1 \\
\text { rank }\end{array}$ & $\begin{array}{l}\text { S-1 } \\
\text { rank }\end{array}$ & $\begin{array}{l}\text { L-1 } \\
\text { rank }\end{array}$ & $\begin{array}{l}\text { Collated } \\
\text { rank }\end{array}$ & $\begin{array}{l}\text { K-2 } \\
\text { rank }\end{array}$ & $\begin{array}{l}\text { S-2 } \\
\text { rank }\end{array}$ & $\begin{array}{l}\mathrm{L}-2 \\
\text { rank }\end{array}$ & Collated & \\
\hline \multicolumn{14}{|l|}{$\begin{array}{l}\text { adverse effects, for example, pain, sleep } \\
\text { problems, etc? }\end{array}$} \\
\hline $\begin{array}{l}\text { Are child-focused strategies (eg, one-to-one } \\
\text { or group social and skills training) effective to } \\
\text { improve confidence, self-esteem and } \\
\text { promote participation in recreation and } \\
\text { leisure activities for children and young } \\
\text { people with neurodisability? }\end{array}$ & 19 & 3 & 14 & 9 & 10 & 18 & 13 & 14 & 16 & 16 & 16 & 16 & 16 \\
\hline $\begin{array}{l}\text { Do cross-sector interventions (eg, key } \\
\text { workers, named contacts to promote } \\
\text { integrated health, social care, education) } \\
\text { improve school attendance, reduce } \\
\text { admissions, and parents' satisfaction and } \\
\text { experience of care for children and young } \\
\text { people with neurodisability? }\end{array}$ & $10=$ & 11 & 23 & 16 & 6 & 19 & 21 & 18 & 18 & 14 & 20 & 17 & 17 \\
\hline $\begin{array}{l}\text { Does promoting public positive attitudes } \\
\text { towards disability improve participation in } \\
\text { recreation and leisure activities for children } \\
\text { and young people with neurodisability? }\end{array}$ & 4 & 16 & $15=$ & 10 & 17 & 9 & 15 & 15 & 17 & 17 & 19 & 18 & 18 \\
\hline $\begin{array}{l}\text { Are dietary modifications/restrictions (eg, } \\
\text { gluten, casein, dairy, meat, etc) effective in } \\
\text { managing symptoms of ASD? }\end{array}$ & 5 & 24 & 13 & 17 & 19 & 25 & 12 & 22 & 22 & 22 & 11 & 19 & 19 \\
\hline $\begin{array}{l}\text { Are oro-motor exercises effective to improve } \\
\text { eating and/or communication for children and } \\
\text { young people with neurodisability? }\end{array}$ & 15 & 15 & 25 & 23 & 22 & 10 & 23 & 20 & 12 & 21 & 22 & 20 & 20 \\
\hline $\begin{array}{l}\text { Are any designs of orthoses (eg, Lycra, } \\
\text { kinesiotaping, plastic, etc) more or less } \\
\text { effective to promote functioning and prevent } \\
\text { deformity for children and young people with } \\
\text { neurodisability? }\end{array}$ & $6=$ & 12 & $10=$ & 6 & 23 & 11 & 18 & 19 & 20 & 19 & 18 & 21 & 21 \\
\hline $\begin{array}{l}\text { Are interventions to improve consistency of } \\
\text { approach between health and education } \\
\text { agencies (eg, keyworkers) effective to } \\
\text { improve behavioural problems in children } \\
\text { with ASD? }\end{array}$ & 13 & 18 & 9 & 11 & 15 & 20 & 20 & 21 & 21 & 20 & 21 & 22 & 22 \\
\hline $\begin{array}{l}\text { What is the (long-term) safety and } \\
\text { effectiveness of drugs used in seizure } \\
\text { management, especially in terms of adverse } \\
\text { effects on learning, psychosis, anxiety, anger } \\
\text { and rage? }\end{array}$ & $23=$ & 22 & $19=$ & 25 & 21 & 23 & 19 & 23 & 23 & 23 & 23 & 23 & 23 \\
\hline
\end{tabular}

adverse effects, for example, pain, sleep

problems, etc?

ren and young

integrated health, social care, education)

ool attendance, reduce

Does promoting public positive attitudes

prability improve participation in

gluten, casein, dairy, meat, etc) effective in

effective to promote functioning and prevent

deformity for children and young people with

Are interventions to improve consistency of

approach between health and education

agencies (eg, keyworkers) effective to

improve behavioural problems in children

management, especially in terms of adverse

effects on learning, psychosis, anxiety, anger

and rage? 


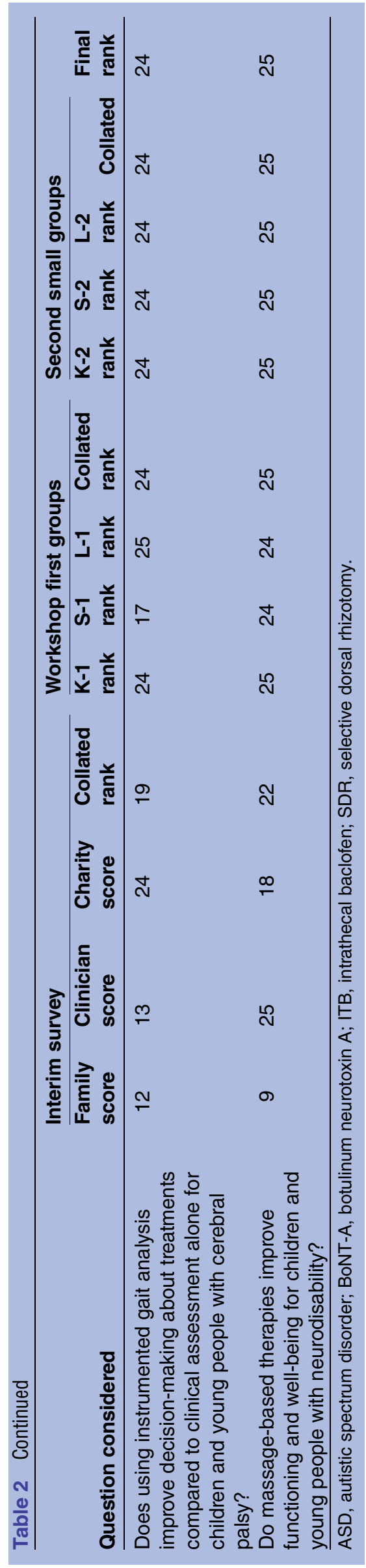

to see benefits for the widest range of disabled children, young people and their families.

The scope of this PSP focused on interventions (things that might be done) to improve the health and well-being of children and young people with neurodisability. Thus, our scope excluded aspects of diagnosis, cure and causal mechanisms. These issues were raised in our survey and have been identified as research priorities in other condition-specific initiatives, for instance for cerebral palsy. ${ }^{19}$ Potential interventions were any environmental factor in the ICF; while there was a predominance of medical and surgical treatments and therapies, suggestions ranged across products and technology, relationships, attitudes, and service organisations and delivery. This indicates the broad ways that participants' perceived health and well-being could be influenced, outside conventional definitions of health services. Thus, our results encourage research on social and educational interventions alongside the research on the effectiveness of medical interventions, and also tailoring and evaluating public health guidance to be appropriate to children and young people with neurodisability. This links well to the NIHR call for "research into the evaluation of public health measures, healthcare interventions and health services to better manage long term conditions in children and young people." (http://www.themedcalls.nihr.ac.uk/children).

Some uncertainties raised in our survey are clearly important topics for research, but were considered outside the scope of this particular initiative, as the agreed scope was to identify interventions that would have an impact on practice in 3-5 years. Examples include stem cell therapies for some conditions and a call for ways to prevent young people with neurodisability coming into contact with the youth-offending service, which has been recognised as an issue. ${ }^{20}$ Transition to adult services was the top priority identified in a North American consensus study ranking research priorities for 'developmental-behavioral paediatrics'. ${ }^{21}$ However, for these topics, it was not possible for the Steering Group to identify any specific intervention that could be evaluated. Such research topics are often approached, in the first instance, as observational studies to understand factors associated with efficient processes and variation in health outcomes ${ }^{22}$; if an intervention can be defined, then effectiveness can be evaluated using an appropriate research design. Our scope focused on children and young people; hence, issues raised in our survey relating to the health and well-being of parent carers were excluded. There is ample evidence that parent carers are at risk of poorer physical and psychological health. ${ }^{23}$ Therefore, evaluating ways to promote their health and well-being is vital.

We also encountered some topics that the JLA considers 'unknown knowns', where research has produced potentially useful findings but people are not aware of them. For example, several parents in the survey raised issues related to how to assess pain in children with 
Box 2 Top 10 research questions agreed as shared priorities

1. Does the timing and intensity of therapies (eg, physical, occupational and speech and language therapy, 'early intervention', providing information, etc) alter the effectiveness of therapies for infants and young children with neurodisability, including those without specific diagnosis? What is the appropriate age of onset/strategies/dosage/direction of therapy interventions?

2. To improve communication for children and young people with neurodisability: $(A)$ what is the best way to select the most appropriate communication strategies? And (B) how to encourage staff/carers to use these strategies to enable communication?

3. Are child-centred strategies to improve children's (ie, peers) attitudes towards disability (eg, buddy or circle of friends, etc) effective to improve inclusion and participation within educational, social and community settings?

4. Does appropriate provision of wheelchairs to enable independent mobility for very young children improve their self-efficacy?

5. Are counselling/psychological strategies (eg, talking therapies) effective to promote the mental health of children and young people with neurodisability?

6. What is the (long-term) comparative safety and effectiveness of medical and surgical spasticity management techniques (botulinum neurotoxin $A$, selective dorsal rhizotomy, intrathecal baclofen, orally administered medicines) in children and young people with neurodisability?

7. Does a structured training programme, medicines and/or surgery speed up the achievement of continence (either/or faecal or urinary) for children and young people with neurodisability?

8. What strategies are effective to improve engagement in physical activity (to improve fitness, reduce obesity, etc) for children and young people with neurodisability?

9. Which school characteristics (eg, policies, attitudes of staff, etc) are most effective to promote inclusion of children and young people with neurodisability in education and afterschool clubs?

10. What is the long-term safety, effectiveness and sustainability of behavioural strategies and/or drugs (eg, melatonin) to manage sleep disturbance in children and young people with neurodisability (outcomes include time to onset, duration, and reducing impact on family)?

communication difficulties. In fact there exist several methods to assess pain for children who cannot selfreport using structured approaches asking parents or carers about behaviours thought to be pain-related. ${ }^{24} 25$ This exemplifies the recognised gap between potential users of research findings and research outputs. Researchers should do more to disseminate outputs to all potential users; there is also a need to educate and empower patients and carers to meet their information needs.

The issues prioritised are the result of the JLA process that involved engaging partner organisations and societies, a survey, checking uncertainties, and interim and
Engage partners

13 charities \& 8 professional societies or special interest groups registered to take part.

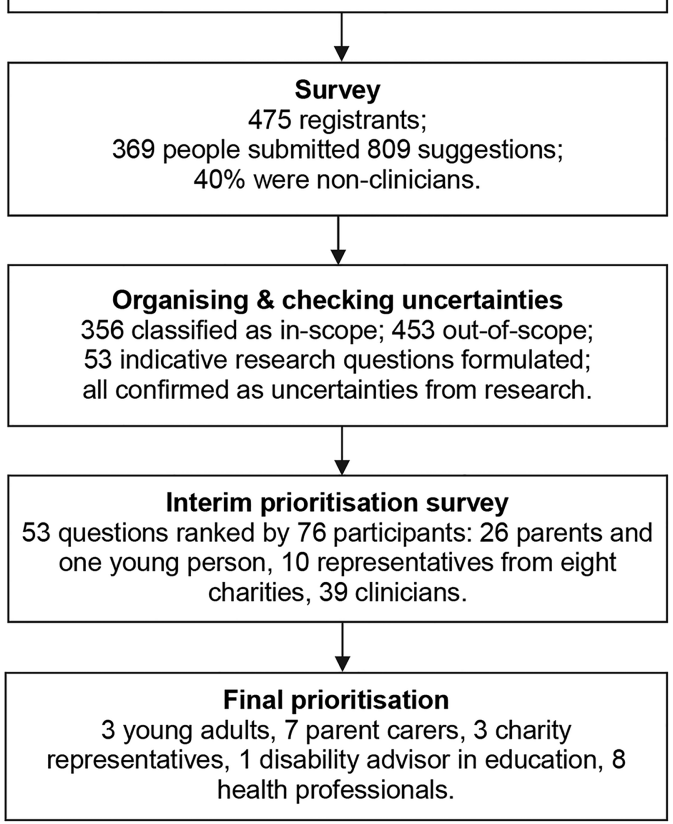

Figure 1 Flow chart showing the process and numbers of participants and research suggestions and questions at each stage.

final prioritisation stages. There are several limitations that should be borne in mind when considering the issues identified and prioritised. Some potential partners did not respond; we failed to engage many professionals from primary care, and few psychology and psychiatry colleagues participated in the process. There was varying engagement of partners over the duration of the project. Our survey used an open question approach that led to large number of suggestions being classified as 'out-of-scope' because a PICO structured research question could not be determined; careful consideration should be given to using a more structured PICO format for future surveys, although such an approach may deter others. The participation of the NNPCF enabled families from around England to take part in the survey and final workshop; nevertheless, those who took part were probably not socioeconomically or ethnically representative of the population.

Another limitation to our survey was the small number of ideas from children and young people in the survey. It is recognised that their perspectives are often not represented in research. ${ }^{26}$ We did try various methods to engage children and young people with neurodisability in the survey; unfortunately, our resources and time were insufficient to engage children and young people meaningfully. The Steering Group was disappointed with this aspect. We do believe that with adequate resources and careful planning, children and young people with neurodisability could play a greater role in the identification of potential research topics. 
For instance, such approaches were successful in capturing children and young people's views to identify key health outcomes in neurodisability. ${ }^{27}$ The context of health research in general and 'treatment uncertainties' in particular would require careful explanation; some creative activity would help to make the engagement accessible for young people. We would encourage colleagues engaging in a research priority setting to plan and deploy adequate resources to capture the views of children and young people, perhaps using focus groups and interviews. On a more positive note, we were pleased that young adults with neurodisability took part in the final workshop, and their preferences and views were captured in the ranking of research priorities.

Previous JLA PSPs have focused on a specific diagnosis. Our non-categorical approach was predicated on the basis that many conditions under the umbrella of neurodisability create similar difficulties, some children with neurodisability are not given a named diagnosis and that we wanted the results to benefit as many young people as possible. Nevertheless, our non-categorical approach to neurodisability may have excluded some specific issues important for particular diagnoses and/or influenced the way suggestions were aggregated and research topic questions framed. There are a large number of UK charities supporting families of children with conditions under the umbrella of neurodisability ${ }^{28}$; although we approached many of these agencies, few condition-specific organisations became partners. Hence, there remain ample opportunities for pursuing similar research PSPs for specific neurodisability conditions or syndromes.

Clearly initiatives to fulfil the growing aspiration to engage patients and carers and non-researcher clinicians in setting the research agenda are challenging. This project used the JLA methodology in the area of paediatric neurodisability and was successful in producing a shortlist of prioritised topics. However, a number of lessons were learned in carrying out the work and we highlight some of these to inform future initiatives. First, stakeholders could have been engaged earlier to set the scope of the project, to consider whether to focus on existing treatments and therapies consistent with tackling 'treatment uncertainties', or take a broader scope to encompass other topics that epidemiological or laboratory-based research could address. Second, identifying issues would benefit from face-to-face question generation where facilitators could help refine emerging topics into PICO-structured research questions. This will be particularly pertinent when engaging with children and young people. Third, aggregating topics is necessary to reduce the large number of topics to a number that is cognitively manageable for the prioritisation stages. This dilutes the more specifically defined research questions into broad topics, which can undermine researchers' perceptions of the utility of the final product. We devised methods for categorising topics as there was little guidance from JLA for carrying out this aspect of the process; however, these methods require further refinement. Finally, key stakeholders to facilitate the move from prioritised topics to answering research questions are researchers and funding agencies. This could be perceived as part of knowledge translation or exchange cycle involving patients, carers and clinicians asking funding agencies to commission and researchers to carry out research to address topics about which they need information to inform decisions.

\section{Author affiliations}

${ }^{1}$ PenCRU, University of Exeter Medical School, University of Exeter, Exeter, UK ${ }^{2}$ Warwick Medical School, University of Warwick, Coventry, UK

${ }^{3}$ National Network of Parent Carer Forums, London, UK

${ }^{4}$ Council for Disabled Children, National Children's Bureau, London, UK

${ }^{5}$ Addenbrookes Hospital NHS Trust, Cambridge, UK

${ }^{6}$ The British Academy of Childhood Disability, London, UK

${ }^{7}$ UK Database of Uncertainties about the Effects of Treatments (UK DUETs), National Institute for Health and Care Excellence, UK

${ }^{8}$ The James Lind Alliance, NIHR Evaluation Trials and Studies Coordinating Centre, Southampton, UK

Acknowledgements The authors are grateful to a large number of people who supported the project or helped with various tasks: colleagues in the BACD Executive and Strategic Research Group; Anna Walker, NNPCF, who made significant contribution in the early stages of the Steering Group and to engage more parent carers to take part in the survey; Rajib Lodh, Consultant in Paediatric Neurodisability, Leeds Children's Hospital, who helped search for research recommendations; staff at partner organisations and societies; Sally Crowe and Leanne Metcalf, from JLA, who facilitated groups at the final workshop; and all who contributed to the survey and prioritisation stages, and participated in the final workshop.

\section{Collaborators On behalf of the British Academy of Childhood Disability} London, UK.

Contributors All authors made substantive contributions to the conception or design of the work, or the acquisition, analysis or interpretation of data for the work. The Steering Group oversaw all aspects of the work (CM, DS, MB, MM, $A A, J D, M F, K R$ and chaired by KC). The project was managed by PenCRU staff (CM, AS and AJ). Specific contributions included reviewing research recommendations (JC, DS and CM), coding the survey submissions (CM and $A J)$, checking uncertainties (CM and DS), managing the data for entry into UK DUETs (AS, CM and MF). All authors were involved in drafting and revising the papers, and approved the final version.

Funding This study was funded by a grant from the Paul Polani Fund, Royal College of Paediatrics and Child Health (RCPCH), which is managed by BACD. The work also benefited from funding from the charity Cerebra for PenCRU staff that managed the project.

Competing interests None.

Provenance and peer review Not commissioned; externally peer reviewed.

Data sharing statement Further data regarding the source of the original submissions to the survey coded under each indicative question are available in UK DUETs (http://www.library.nhs.uk/duets/SearchResults.aspx? catID=15613).

Open Access This is an Open Access article distributed in accordance with the Creative Commons Attribution Non Commercial (CC BY-NC 4.0) license, which permits others to distribute, remix, adapt, build upon this work noncommercially, and license their derivative works on different terms, provided the original work is properly cited and the use is non-commercial. See: http:// creativecommons.org/licenses/by-nc/4.0/

\section{REFERENCES}

1. Department of Health. NHS Constitution for England 2013. https:// www.gov.uk/government/publications/the-nhs-constitution-forengland (accessed 28 Jun 2014). 
2. INVOLVE. Supporting public involvement in NHS, public health and social care research. Hampshire: UK, 2011. http://www.invo.org.uk (accessed 28 Jun 2014).

3. Staley K. Exploring Impact: public involvement in NHS, public health and social care research. Eastleigh: INVOLVE, 2009.

4. Brett J, Staniszewska S, Mockford C, et al. Mapping the impact of patient and public involvement on health and social care research: a systematic review. Health Expect 2014;17:637-50.

5. Morris C, Shilling V, McHugh C, et al. Why it is crucial to involve families in all stages of childhood disability research. Dev Med Child Neurol 2011;53:769-71.

6. Stewart R, Oliver S. A systematic map of studies of patients' and clinicians' research priorities. Oxford, England: James Lind Alliance, 2008. http://www.lindalliance.org/Map_studies_patients_clinicians research priorities.asp (accessed 28 Jun 2014).

7. Tallon D, Chard J, Dieppe P. Relation between agendas of the research community and the research consumer. Lancet 2000;355:2037-40.

8. Chalmers I, Glasziou P. Avoidable waste in the production and reporting of research evidence. Lancet 2009;374:86-9.

9. Oliver SR. How can health service users contribute to the NHS research and development programme? BMJ 1995;310:1318-20.

10. Partridge $\mathrm{N}$, Scadding J. The James Lind Alliance: patients and clinicians should jointly identify their priorities for clinical trials. Lancet 2004;364:1923-4.

11. Cowan K. The James Lind alliance: tackling treatment uncertainties together. J Ambul Care Manage 2010;33:241-8.

12. Morris $\mathrm{C}$, Janssens $\mathrm{A}$, Tomlinson $\mathrm{R}$, et al. Towards a definition of neurodisability: a Delphi survey. Dev Med Child Neurol 2013;55:1103-8.

13. Bishop DV. Which neurodevelopmental disorders get researched and why? PLOS ONE 2010;5:0015112.

14. British Academy of Childhood Disability. Strategic Research Group 2014. http://www.bacdis.org.uk/research (accessed 28 Jun 2014).

15. World Health Organisation. International Classification of Functioning, Disability and Health. Geneva, Switzerland: WHO, 2001.
16. Cowan K, Oliver S. The James Lind Alliance Guidebook. 2010. http://www.jlaguidebook.org (accessed 28 Jun 2014).

17. World Health Organization \& World Bank. World report on disability. Geneva, Switzerland: WHO, 2011.

18. Fink A, Kosecoff J, Chassin M, et al. Consensus methods: characteristics and guidelines for use. Am J Public Health 1984;74:979-83.

19. Mclntyre S, Novak I, Cusick A. Consensus research priorities for cerebral palsy: a Delphi survey of consumers, researchers, and clinicians. Dev Med Child Neurol 2010;52:270-5.

20. Hughes $\mathrm{N}$, Williams $\mathrm{H}$, Chitsabesan $\mathrm{P}$, et al. Nobody made a connection: the prevalence of neurodisability in young people who offend. Office of the Children's Commissioner for England, 2012. http://www.childrenscommissioner.gov.uk/content/publications/ content 633 (accessed 24 Jun 2014).

21. Blum NJ, Feldman HM, Barbaresi WJ, et al. Research priorities for developmental-behavioral pediatrics: a DBPNet consensus study. J Dev Behav Pediatr 2012;33:509-16.

22. Colver AF, Merrick H, Deverill M, et al. Study protocol: longitudinal study of the transition of young people with complex health needs from child to adult health services. BMC Public Health 2013;13:1471-2458.

23. Brehaut JC, Garner RE, Miller AR, et al. Changes over time in the health of caregivers of children with health problems: growth-curve findings from a 10-year Canadian population-based study. Am J Public Health 2011;101:2308-16.

24. von Baeyer CL, Spagrud LJ. Systematic review of observational (behavioral) measures of pain for children and adolescents aged 3 to 18 years. Pain 2007;127:140-50.

25. Hunt A, Goldman A, Seers K, et al. Clinical validation of the paediatric pain profile. Dev Med Child Neurol 2004;46:9-18

26. Hallet $\mathrm{C}$, Prout A. Hearing the voices of children: social policy for a new century. Routledge, 2003.

27. Allard A, Fellowes A, Shilling V, et al. Key health outcomes for children and young people with neurodisability: qualitative research with young people and parents. BMJ Open 2014;4:e004611.

28. Contact a Family. AtoZ of conditions. 2014. http://www.cafamily.org. uk/medical-information/conditions (accessed 24 Jun 2014). 